\author{
Military Technical College \\ Kobry Elkobbah, Cairo, \\ Egypt.
}

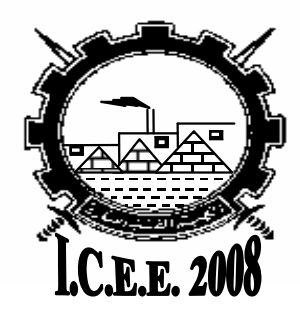

$4^{\text {th }}$ International Conference On Chemical \& Environmental Engineering 27-29 May 2008

\title{
Studying The Thermal Obscuring Potential Of Some Mineral Dust Mixtures (Calcium carbonate and carbon black mixtures)
}

\author{
H. Ramzy ${ }^{*}$, M. Sh. Fayed", M. K. Abd El Magid ${ }^{* * *}$, \\ T. Melliegy *, W. Magdy*
}

\begin{abstract}
A promising approach to the developments of countermeasures against emerging threats such as imaging infrared seekers is to successfully combine obscuration and decoy technologies with modern development capabilities. Carbon black performs well as a perfect obscuring material, but it also has undesirable properties. The experimental studies concern with investigating the thermal screening potential of binary mixtures of calcium carbonate and carbon black to find the possibility of developing an airborne mixtures with the enhanced thermal attenuation and the minimum carbon black percentage. The smoke was generated pneumatically within a designed smoke tunnel equipped with means for measuring the surrounding meteorological parameters such as the ambient temperature, and relative humidity. The thermal obscuring potential of the smoke cloud was tested by using a infrared camera attached to a video recorder and a data processing system. The effect of the smoke cloud on the attenuation of the infrared radiation emitted from a selected target was recorded, analyzed and explained.
\end{abstract}

\section{KEY WORDS}

Infrared countermeasures, powder, screening, smoke, obscurants

* Egyptian Armed Forces, Egypt.

** Prof. of Chem. Eng., MTC, Egypt.

${ }^{* * *}$ Assistant Prof. of Chem. Eng., MTC, Egypt 


\section{INTRODUCTION}

Warfare conditions and tactics require that land, sea, and air forces be trained with the best defensive systems available. Among these systems, smokes obscurants have long been employed to mask the movements of both ground and sea forces. However, the modern battlefield has become much more complex, with visual detection being augmented or replaced by a wide range of electromagnetic methods for detection and targeting. One result is a need for specific types of electromagnetic smoke obscurants [1-3]. Tactical military electro-optics wavelength range encompasses the portion of the electromagnetic spectrum from approximately 0.4-micrometer wavelength to 15 micrometers. There are two atmospheric windows in the range 3-5 um and 8-12 um and extensively used by electrooptics systems [4-6]. The EO sensing and guidance system technology can be divided into three broad classes of devices non-imaging IR systems, Imaging IR systems, and Laser guidance system $[7,8]$. Whatever the advent of military electro-optic systems and their guidance systems, The working key of all the advent systems in the present and future; depend totally on the senescing of the received infrared photons which emitted from the target. If these photons are prevented to reach, the detection systems of the most advent electro-optic system will not sense the target.

A promising approach to the developments of countermeasures against imaging infrared seekers is airborne obscurants. Airborne obscurants could be considered as common name for most mechanical smoke systems, which concerned with means to aerosolize highaspect ratio solid particles with minor dimensions below one micron. Recent studies concerns with investigating different chemical candidates that can be used to develop effective smoke obscurant technologies to protect a wide range of military assets deployed throughout the world [9 -11]. Electrically conductive fibers, metal flakes, and mineral dusts (nano-particles are interesting candidates) were investigated from the point view of thermal obscuring potentials [12-15]. Traditional dissemination mechanisms are explosively bursting of compact mass of the obscuring materials, and pneumatic discharge of the obscuring powder $[16,17]$.

Carbon black was investigated an obscurant to screen electromagnetic tracking and targeting systems. Recent studies proved that carbon black perform well in obscuring infrared bands as well as of visible band $[9,18,19]$. Carbon black is considered to be a combustible solid, but it is difficult to ignite or sustain combustion once fire or ignition source is removed. Its powders or dusts in mixture with air may present a greater combustion hazard. Hazardous reactions occur when carbon black comes into contact with very strong oxidizers. These characteristic require special consideration during any emergency involving a leak or release of carbon black powder. Carbon black is electrically conductive; exercise caution when handling in areas where contact with electrical circuitry is possible. Handle and transfer in a manner that avoids excessive dusting [20-22].

The objective of this study is to investigate the thermal screening potentials of binary mixtures of carbon black and calcium carbonate, which is a relatively inert material and considered to be a noncombustible solid powder [23]. The experimental studies concern with investigating the possibility of developing airborne mixtures with the heights thermal attenuation and the optimum carbon black percentage. 


\section{Experimental work}

In this part of work the used chemicals, instruments, and measurement setup were described briefly. The procedures of sample preparation, thermal measurements, and data analysis were discussed briefly.

\subsection{Chemicals}

All the chemicals used in this experimental work were of the commercial grade. They were used directly without any purification or treatment. These chemicals and their toxicity limits are shown in the following table (2.1).

\subsection{Instruments}

The used instruments during different steps of the experimental work are illustrated in table (2.2). The thermal characteristics of the produced cloud of smoke were measured by thermal imager model 760 LW Inframetrics of spectral range from 8$12 \mu \mathrm{m}$. It was equipped with TV\&videocassette recorder model Panasonic TC4SV10S to record the thermal image of the infrared black body radiator model Graseby201/546, which was taken to be an ideal target of absolute calibration accuracy and temperature stability $\pm 2{ }^{\circ} \mathrm{C}$. Thermal characteristics and data were processed and analyzed with IBM computer model 300PL pintum III series, 1.2GH processor. The relative humidity values were measured by digital thermo-hygrometer model TFA 4001. Weighing was performed using digital balance type Stanton digital balance model 351BR. Drying was carried out by drying oven of type Veb-mlw model WS3.

Experimental setup consists mainly of specialy designed smoke tunnel, thermal imager, data acquisition system and infrared black body. The smoke tunnel basic specifications are given in table (2.3). It is equipped with suction and recycling fans as well as measuring apparatuses to record humidity, and temperature. The smoke was generated pneumatically in the tunnel by dispersion of the powder sample within sample holder which made of PVC. Figure (2.1) shows dimensional disassembly and assembly drawing of the sample holder. The maximum mass could be loaded in this holder was about $100 \mathrm{~g}$. The infrared black body radiator was used to represent a field target. The thermal imager and the accompanied devices for recording and processing were placed at the other end. An air curtain is applied in front of them to prevent the smoke from diffusion in the space of laboratory. The effect of smoke in reducing temperature and radiation level of the infrared black body radiator with time was recorded, graphed and analyzed for each smoke sample. The setup used for measurements is illustrated in figure. (2.2).

\subsection{Experimental studying of obscuring potentials of smoke powders.}

The smoke was generated in the smoke tunnel by pneumatic mechanism, where the outlet air from the tunnel blower disperses the smoke powder in the sample holder pushing it into the smoke tunnel in the front of the infrared black body radiator and so 
the smoke cloud is propagated in the tunnel. Thermal characterization of the smoke cloud was investigated by measuring the attenuation of the infrared radiation through the smoke cloud and calculating the thermal transmittance of each smoke powder.

\subsubsection{Preparation of Smoke Powder Samples}

The smoke samples before testing were dried and particle size was analyzed with sieves .The mixtures were prepared by mixing their constituents in suitable rotating drum, and then it is sieved with $90 \mu \mathrm{m}$ sieve by Dental vibrator model DV34. The mixture is mixed again in rotating drum for an hour then sieved again. This step is repeated five times to insure complete mixing The smoke samples were weighed with the following masses, $15 \mathrm{~g}, 25 \mathrm{~g}, 50 \mathrm{~g}, 75 \mathrm{~g}$, and $100 \mathrm{~g}$.

\subsubsection{Testing of Smoke Powder Samples}

(8) The sample under testing was placed in the sample holder by a suitable glass funnel, and then the stopper of the holder was tightened very well.

(9) The smoke tunnel circulation system and the videocassette recorder are turned on at the same time. The outlet air from the tunnel blower disperses the smoke powder sample in the sample holder pushing it into the smoke tunnel in the front of the infrared black body radiator and so the smoke cloud propagated in the tunnel.

(10) The change in the observed temperature of the infrared black body radiator during the propagation of the smoke cloud in the tunnel and the disappearance of target thermal image is recorded on the video tape.

(11) The setup is turned off when the observed temperature of the infrared camera reaches its initial value before testing.

(12) The smoke tunnel circulation system is turned on again for 10 min to remove any residual powders in the tunnel from the previous experiment, and then turned off for $10 \mathrm{~min}$. This step is repeated three times to insure no residuals after each experiment.

(13) Every sample is tested five times to insure consistency and to minimize the experimental error.

(14) After testing the sample, the smoke tunnel circulation system is turned on for 30 min then turned off for $15 \mathrm{~min}$. This step is also repeated three times; assure that the infrared camera observes no change in the initial temperature of the target when circulation system is turned on with empty tunnel.

\subsubsection{Data Analysis}

The data was gathered by playing the videotape in a slow motion. The variation in the temperature of infrared radiator caused by the smoke sample was tabulated with time. The transmittance of infrared radiation in the range of 8-14 micrometer through the smoke cloud is calculated [24].

\section{Results and Discussion}

The binary mixtures of carbon black and calcium carbonate that were investigated having the following different percentage of carbon black $2.5,5,10,15$ and $20 \%$ that 
corresponding to mixtures (1-5). Five different amounts of each mixture were chosen for the investigation. Namely, 15, 25, 50, 75 and $100 \mathrm{~g}$ of the smoke powders were loaded in the sample holder for pneumatic dispersion within the tunnel, which are corresponding to maximum proposed smoke concentrations of $1.7,2.8,5.7,8.5$, and $11.3 \mathrm{~g} / \mathrm{m}^{3}$ respectively. The experiments were carried out with special designed smoke tunnel of total volume $8.85 \mathrm{~m}^{3}$, at $18^{\circ} \mathrm{C}$ ambient temperature and relative humidity $35 \%$ and the black body radiator was at $100^{\circ} \mathrm{C}$.

These proposed smoke concentrations were estimated by dividing the mass loaded in the smoke tunnel by its total volume, assuming that the maximum thermal attenuation occurs when the mass loaded is totally dispersed homogeneously in the tunnel with neglecting any losses. Two datums were selected at $80 \%$ and $90 \%$ thermal attenuation to compare between the tested samples. The selection of these two values was based on the obtained results as they are relatively high values and most of the tested samples reach one or both of them.

It was found that thermal transmittance decreases during the propagation of the smoke cloud in the smoke tunnel due to the increase in concentration of the smoke materials. The minimum thermal transmittance occurs during experiment when the mass loaded in the tunnel achieves the maximum concentration, assuming homogenous distribution of the smoke cloud in the tunnel. After achieving maximum concentration of the smoke material, the concentration decreases due to gravitational sedimentation and so the thermal transmittance increases again. The rate of obscuration increases as the mass loaded in the smoke tunnel increased. The obtained results are summarized in table (3.1). The effect was so successful when testing binary mixtures of calcium carbonate and carbon black with different masses percentage of carbon black. The graphical presentation of the picked up results is shown in Figures (3.1) to (3.5). There was noticed an appreciable increase in the maximum thermal attenuation from $92.8 \%$ to $100 \%$, with the increase the mass percentage of carbon black in the tested mixtures from $2.5 \%$ to $20 \%$. In addition, there was a remarkable increase in the period of duration of their maximum thermal attenuation.

Figure (3.1) shows the effect of mixture (1) smoke clouds produced by different masses which containing $2.5 \%$ carbon black on the thermal transmittance of infrared radiation. By increasing the mass loaded in the sample holder from 15 to $100 \mathrm{~g}$, the maximum attenuation of thermal radiation of the black body augments from $52.1 \%$ to $92.8 \%$ with a corresponding increase in the duration of this maximum attenuation from one to $7.1 \mathrm{sec}$.

By subjecting the target to mixture (2) which contains $5 \%$ carbon black with different masses, a group of curves of similar trend is shown in figure (3.2). The same principle discussed before with the pervious mixture has been applied successfully, but to a higher extent of thermal attenuation using the same masses under the same applied conditions. The thermal attenuation augments from $59 \%$ to $94.6 \%$ with a corresponding increase in the duration of this maximum attenuation from one to $2.3 \mathrm{sec}$ respectively. 
By subjecting the target to mixture (3) of higher percentage of carbon black reaches $10 \%$ with different masses, a group of curves of similar trend is shown in figure (3.3), a higher extent of thermal attenuation using the same amount of mass under the same applied conditions. The thermal attenuation augments from $74 \%$ to $95.6 \%$ with a corresponding increase in the duration of this maximum attenuation from one to $2.5 \mathrm{sec}$ respectively.

Figure (3.4) shows the obtained results when increasing the percentage of carbon black to be $15 \%$, higher extent of thermal attenuation was achieved using the same amounts of mixture (4) mass under the same applied conditions. The thermal attenuation increases from $78.8 \%$ to $100 \%$ with a corresponding increase in the duration of this maximum attenuation from $1.5 \mathrm{sec}$ to $4.5 \mathrm{sec}$ respectively.

The effect was so successful when testing mixture (5) which contains $20 \%$ carbon black. Figure (3.5) shows the highest extent of thermal attenuation using the same masses under the same applied conditions. The thermal attenuation increases from $85.5 \% \%$ to $100 \%$ with a corresponding increase in the duration of this maximum attenuation from $1.5 \mathrm{sec}$ to $5.1 \mathrm{sec}$ respectively.

Review of the discussed results was tabulated in table (3.1) to show the variation of the thermal attenuation and its duration periods of the tested mixtures as function of the disseminated masses and the percentage of carbon black in the binary mixtures with calcium carbonate. The results were obtained assuming complete homogeneity of the dissipated binary mixture in the tunnel and the showed minimums were proposed to be at the higher expected mass concentration of the smoke producing powders.

It was found that the increase in the percentage of carbon black increases the maximum attenuation and its duration time. It was concluded that $50 \mathrm{~g}$ mass loaded of mixture (5) which corresponding to maximum proposed concentration in the tunnel $5.6 \mathrm{~g} / \mathrm{m}^{3}$ and contains only $20 \%$ carbon black is the minimum mass loaded of the mixtures that sufficient for achieving $100 \%$ thermal transmittance attenuation. To achieve the same maximum thermal transmittance attenuation $75 \mathrm{~g}$ mass loaded of mixture (4) which corresponding to maximum proposed concentration $8.5 \mathrm{~g} / \mathrm{m}^{3}$ and contains $15 \%$ carbon black is sufficient. Figure (3.6) shows the variation of the mixtures thermal transmittance with the smoke concentration .The minimum thermal transmittance achieved by mixtures (1-5) are $0.07,0.05,0.04$,zero and zero respectively The minimum smoke concentrations sufficient to achieve their minimums thermal transmittance are 11.3, $11.3,11.3,8.5$, and $5.65 \mathrm{~g} / \mathrm{m}^{3}$ respectively. It was found that the addition of carbon black to calcium carbonate improves the thermal transmittance attenuation of calcium carbonate. The minimum smoke mixture concentration sufficient for $100 \%$ thermal transmittance attenuation was $5.7 \mathrm{~g} / \mathrm{m}^{3}$ of mixture (5). The minimum smoke concentration sufficient for $90 \%$ thermal transmittance attenuation was $2.1 \mathrm{~g} / \mathrm{m}^{3}$ of mixture (5). The minimum smoke concentration sufficient for $80 \%$ thermal transmittance attenuation was $1.6 \mathrm{~g} / \mathrm{m}^{3}$ of mixture (5). It is clear that the addition of carbon black 
enhances the thermal screening potential of calcium carbonate with different degrees at the same weight percentage of carbon black in their mixtures.

\section{CONCLUSIONS}

The main conclusions of the present work are:

(1) The addition of carbon black to calcium carbonate enhances their thermal obscuring potentials depending on the weight percentage of carbon black

(2) It is possible to achieve acceptable obscuring potential by using mixtures of calcium carbonate with minimum mass percentage of carbon black (15-20\%).

\section{REFERENCES}

[1] Headquarters Departments of USA Army, "Smoke Operations", Field Manual 3-50, Washington, DC, 1990.

[2] Headquarters Departments of USA Army, "Military Chemistry and Chemical Compounds", Field Manual 3-9, Washington, DC, 1975.

[3] Brian A. B., "Smoke and Obscurant Operations in a Joint Environment", Research Report, Air Command and Staff College, Air University, United States Army, 1998.

[4] Ronald G. D., Paul C., and Timorthy E.,"Introduction to Infrared and ElectroOptical Systems", Artech House Press, 1999.

[5] Hudson R. D.; "Infrared System engineering “ ; $1^{\text {st }}$ Edition , John Wiley Press, 1975

[6] Goussorgues G.; "Infrared Thermograph"; Chapman and Hall Press, 1998

[7] Ahmed A. A.;" IR/Laser Guidance and Image Tracking Systems and Their Countermeasures", Ph.D., M. T. C., Cairo,2001

[8] Soliman O. E.;" Countermeasures for Optoelectronic guided Weapons", MSc., M. T. C., Cairo, 2001.

[9] Ladouceur H.D,. Baronovski A.P and Nelson H.H., "Obscurants for Infrared Countermeasures III", Naval Research Laboratory, Washington, Dc, 2001.

[10] Ladouceur H.D,. Baronovski A.P and. Nelson H.H, "Obscurants for Infrared Countermeasures", Naval Research Laboratory, Washington, DC, 1997.

[11] Ladouceur H.D,. Baronovski A.P and. Nelson H.H, "Obscurants for Infrared Countermeasures II", Naval Research Laboratory, Washington, DC, 2000

[12] Larmignat D., Morand P., Prieur C. and Lacreuse G., "Material For Efficient Masking in The Infrared Region ", Patent Number: US 5340395, 1994

[13] Susan T.P., Kristen J .M., Alan H. G.,. Terry R. L. and Mitchell R. Z., "Conductive Polymer Blends for Non toxic Obscurant Materials", US Army Edgewood Chemical Biological Center.

[14] Janon E., "Optimum Smoke Nanoparticles That Maximize Attenuation at Infrared and Radar Wavelengths", Edgewood Chemical Biological Center, 2002.

[15] USA Army Chemical and Biological Defense Agency "Screening Smoke of Commercially Available Powders: Infrared Screening by Graphite Flake ", Washington, MD, 1993

[16] Wulvik E., "Arrangement in Smoke Camouflage System", Patent Number: US 5233927, 1993. 
[17] Sellmen L. R, Embury J. R. and Beyth W. W., "Method Of Forming IR Smoke Screen", Patent Number: US 4704966, 1987.

[18] 111 H. Ramzy, M. Sh. Fayed, M.Kassem, and T. Milliegy, "Studying of The Thermal Obscuring Potentials Of Some Mineral Dusts", $3^{\text {rd }}$ International Conference on Chemical \& Environmental Engineering, Military Technical College ,Cairo, Egypt May2005

[19] Jinyu Z., Mun Y. C., George W. M. and Louis A. G., " Soot Scattering Measurements in The Visible and Near Infrared Spectrum", Proceedings of The Combustion Institute, Vol. 2, P. 439-446, 2000.

[20] Bretherick L.; "Handbook of Reactive Chemical Hazards", fourth Edition, Butterwarths Press, 1990.

[21] 78 Hugh O. P.; "Handbook of Carbon, Graphite, Diamond, and Fullerences" Noyes Publications, 1993.

[22] Kim K.; "Carbon: Electrochemical and Physicochemical Properties", John Wiley Press, 1998

[23] George W. "Handbook of Fillers", $2^{\frac{\text { nd }}{1}}$ Edition, Chem. Tec. Publishing, 2000.

[24] H. Ramzy, "Generation And Chracterization Of Some Arososles Agianest Infrared Sensors", MSc. , MTC, Cairo,2005.

[25] Greenwood N.N and Eanshaw A., "Chemistry of Elements", Pergmon Press, 1984.

[26] David R, "CRC Handbook of Chemistry and Physics", CRC Press, Boca Raton, 1994.

[27] Richard J., and Lewis S. "Hazardous Chemicals Desk Reference", Fifth Edition, John Wiely Press, 2003. 
Table (2.1) Chemicals used in the present work and their toxicity limits [25-27].

\begin{tabular}{|c|c|c|}
\hline $\begin{array}{c}\text { Smoke producing } \\
\text { powder }\end{array}$ & Calcium carbonate & Carbon black \\
\hline Chemical formula & $\mathrm{CaCO}_{3}$ & $\mathrm{C}$ \\
\hline $\mathrm{M} \cdot \mathrm{wt}(\mathrm{g} / \mathrm{mol})$ & 100.09 & 12.011 \\
\hline Particle size range $(\mu \mathrm{m})$ & $0.2-30$ & $1.4-25$ \\
\hline Density $\left(\mathrm{g} / \mathrm{cm}^{3}\right)$ & 2.93 & $1.8-2.1$ \\
\hline $\mathrm{TLV}^{*}\left(\mathrm{mg} / \mathrm{m}^{3}\right)$ & 15 & 3.5 \\
\hline Supplier & $\begin{array}{c}\text { MENA company } \\
\text { (Egypt) }\end{array}$ & $\begin{array}{c}\text { Columbian chemical } \\
\text { company (USA) }\end{array}$ \\
\hline
\end{tabular}

* TLV.....Threshold Limit Value

Table (2.2) Instruments used in the present experimental work.

\begin{tabular}{|c|c|c|c|}
\hline No & Instruments & Model & Using \\
\hline 1 & Thermal imager & Inframetrics 760 LW & Experimental setup \\
\hline 2 & TV videocassette recorder & $\begin{array}{c}\text { PanasonicTC- } \\
\text { 14SV10S }\end{array}$ & Experimental setup \\
\hline 3 & Infrared black body radiator & Graseby201/546 & Experimental setup \\
\hline 4 & Sample holder & Local fabrication & Experimental setup \\
\hline 5 & Smoke tunnel & Local fabrication & Experimental setup \\
\hline 6 & Digital thermo-hygrometer & TFA 4001 & Experimental setup \\
\hline 7 & Wind velocity meter & Waren H128 & Experimental setup \\
\hline 8 & PC computer & Pintum III 300PL & Data Analysis \\
\hline 9 & Digital balance & Stanton 351BR & Sample preparation \\
\hline 10 & Drying oven & VEB-MLW WS3 & Sample preparation \\
\hline 11 & Dental vibrator( Sieving) & DV34 & Sample preparation \\
\hline 12 & Mixing unit (rotating drum) & Local & Sample preparation \\
\hline
\end{tabular}

Table (2.3) Basic specification of the used smoke tunnel [24].

\begin{tabular}{||c|c||}
\hline Item & Specification \\
\hline Material & iron sheets \\
\hline Cross-section & $0.8 \times 0.8 \mathrm{~m}$ \\
\hline Length & $6 \mathrm{~m}$ \\
\hline $\begin{array}{c}\text { Average air } \\
\text { velocity }\end{array}$ & $0.4 \mathrm{~m} / \mathrm{s}$ \\
\hline Total volume & $8.85 \mathrm{~m}^{3}$ \\
\hline Blower power & $2 \mathrm{hp}$ \\
\hline
\end{tabular}




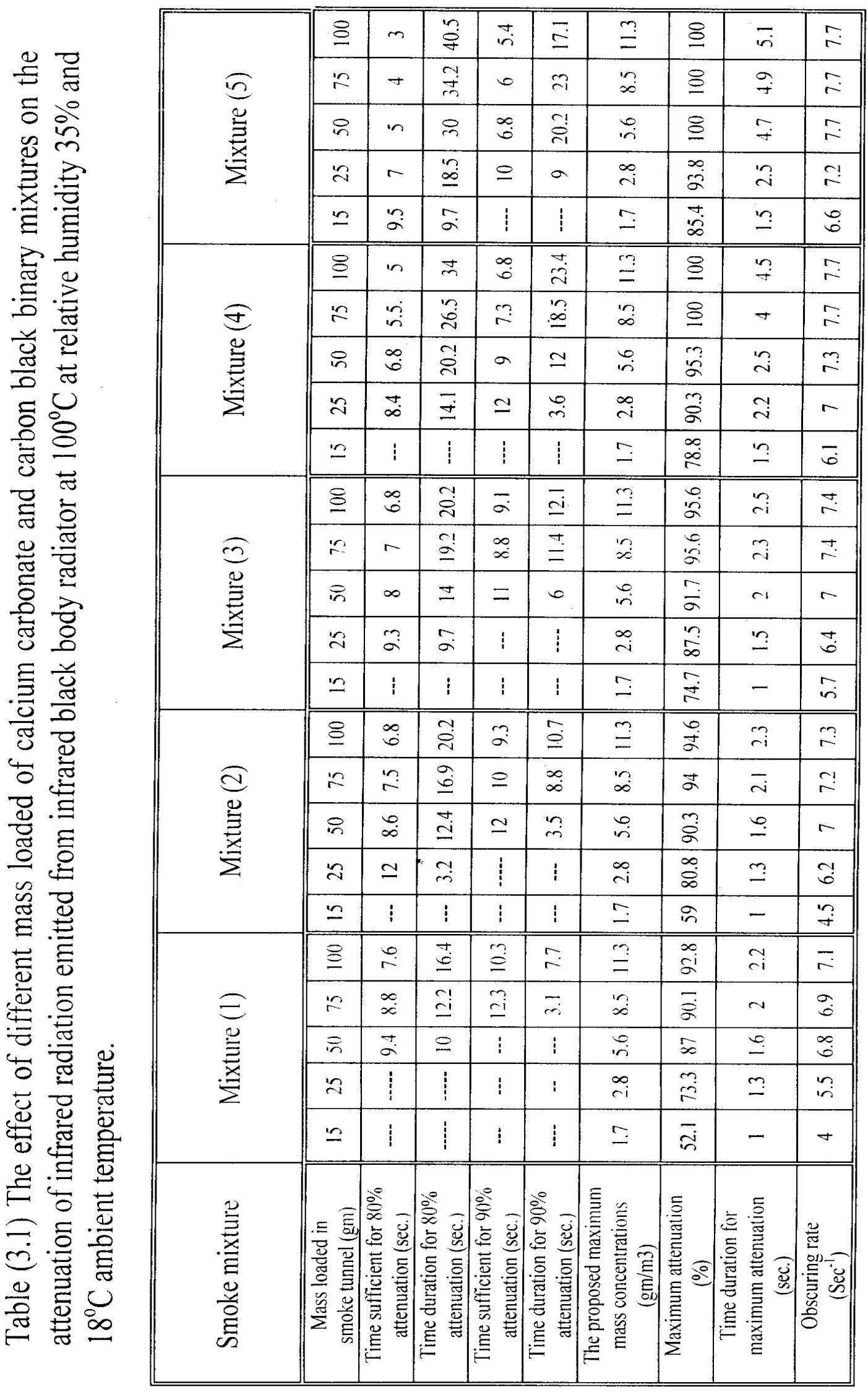




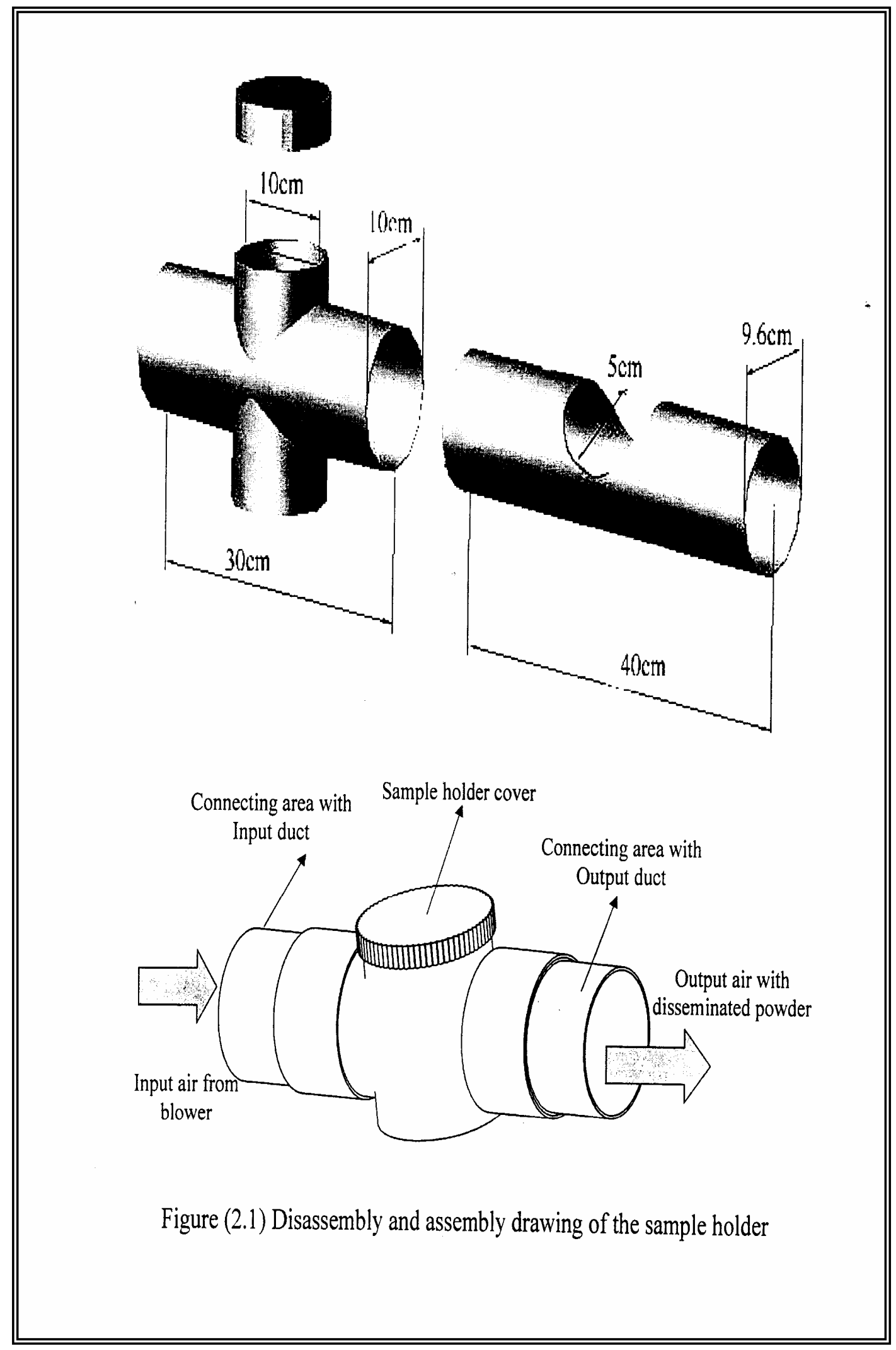




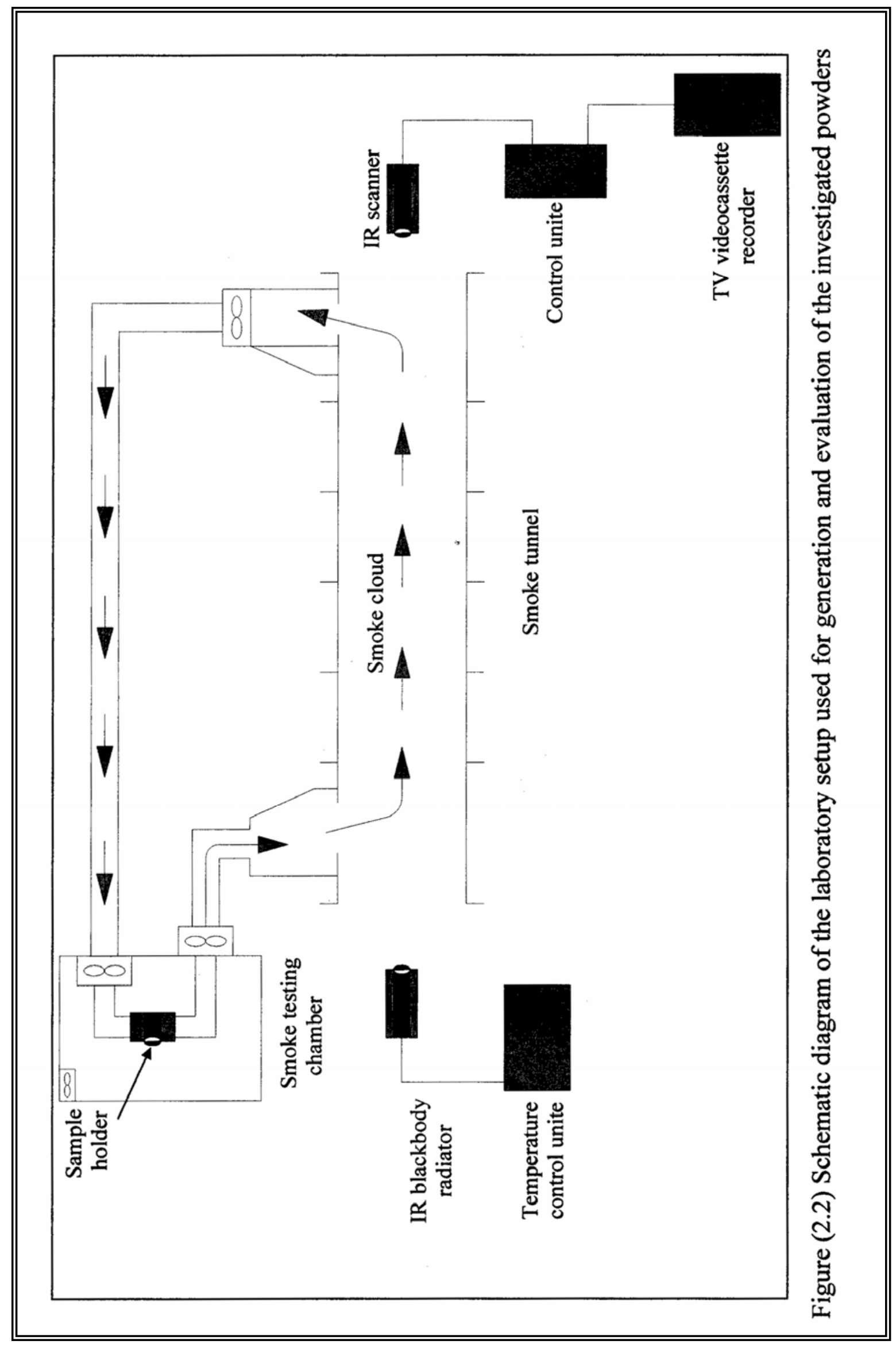




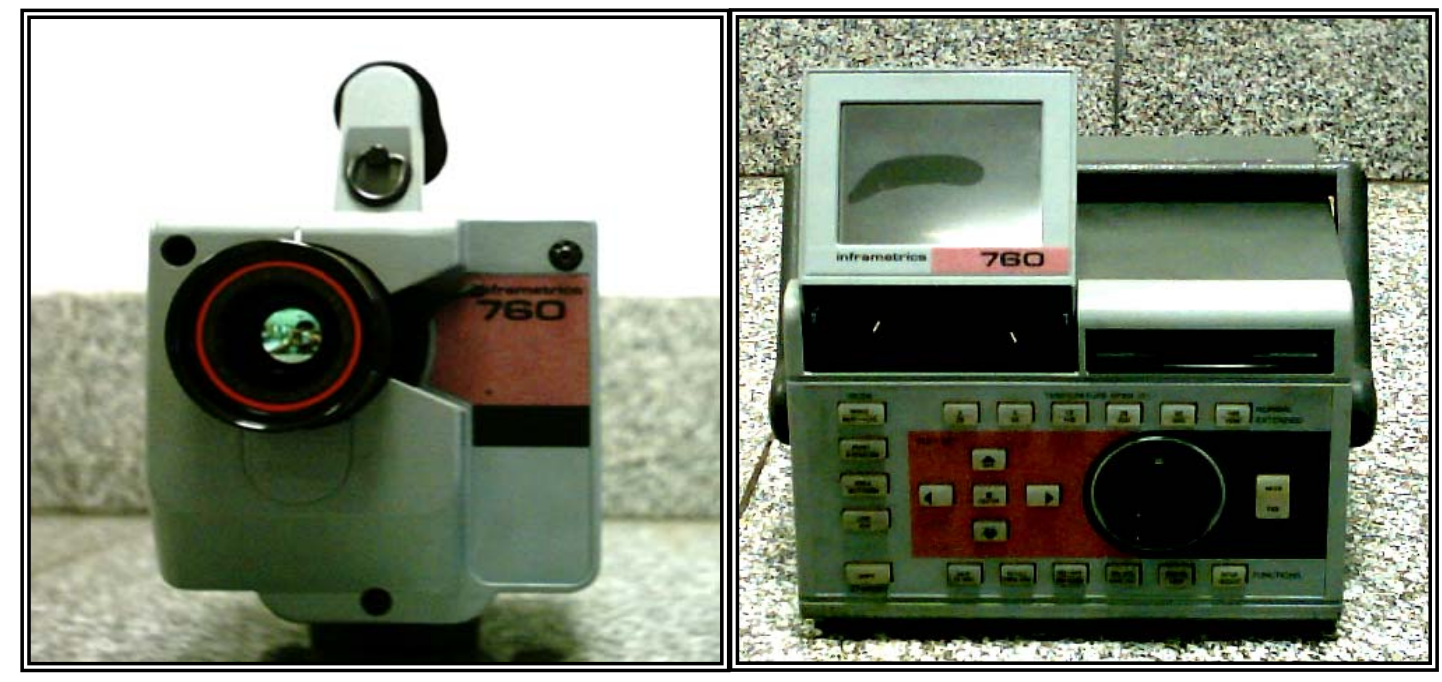

(a)

(b)

Figure (2.3) Inframetrics Infrared Radiometer model 760 IR Imaging Radiometer. (a) Inframetrics 760 thermal scanner. (b) Inframetrics thermal imageprocessing systems

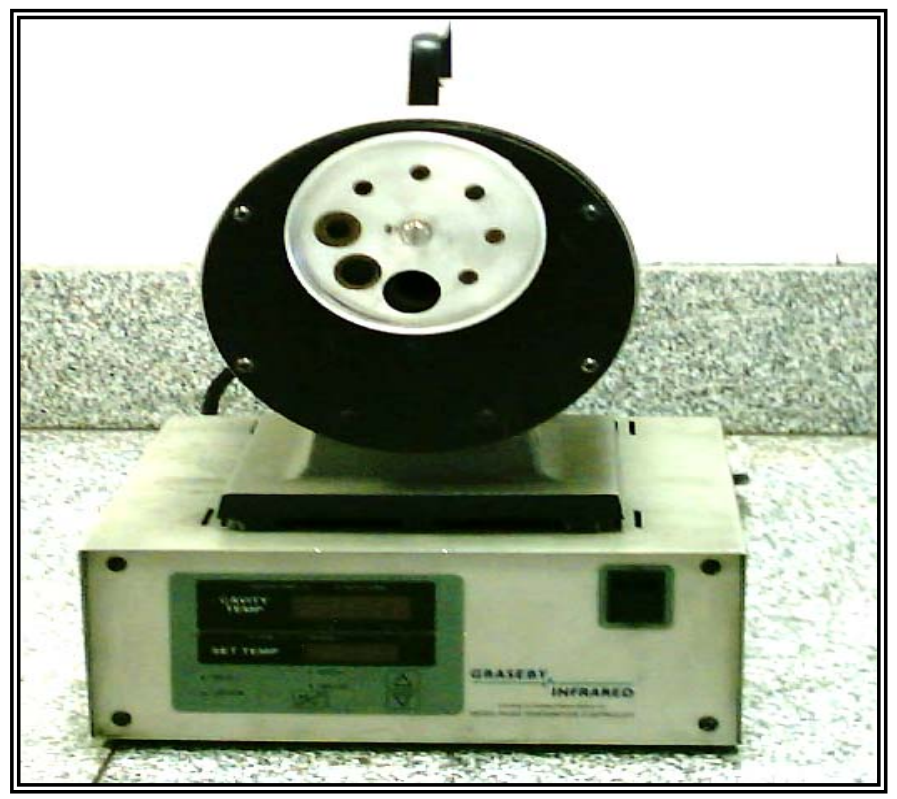

Figure (2.4) Graseby infrared black body radiator with temperature controlling unit 


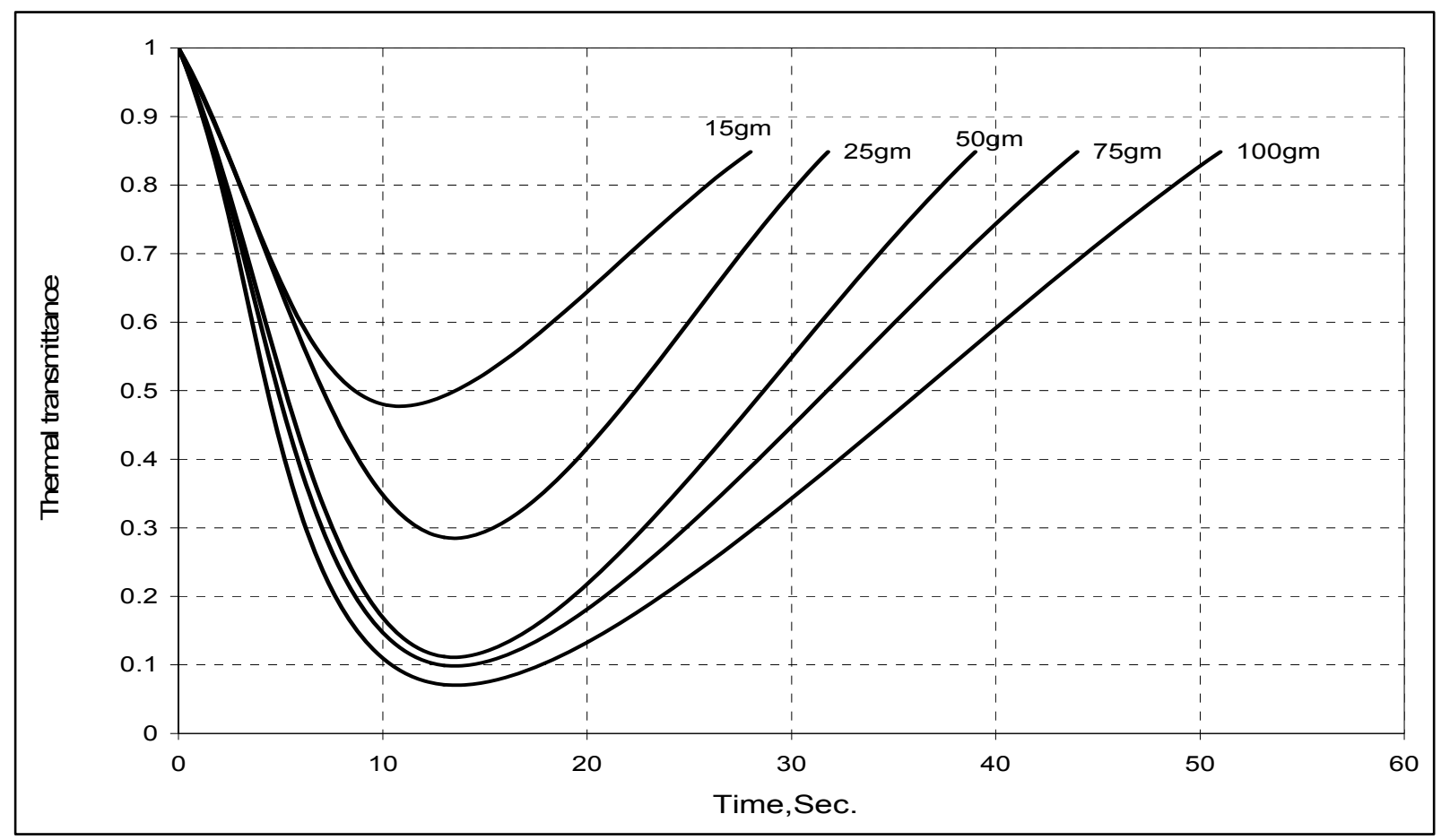

Figure (3.1) the attenuation of infrared radiation emitted from black body radiator at $100 \circ \mathrm{C}$ by mixture (1) at relative humidity $35 \%$ and $180 \mathrm{C}$

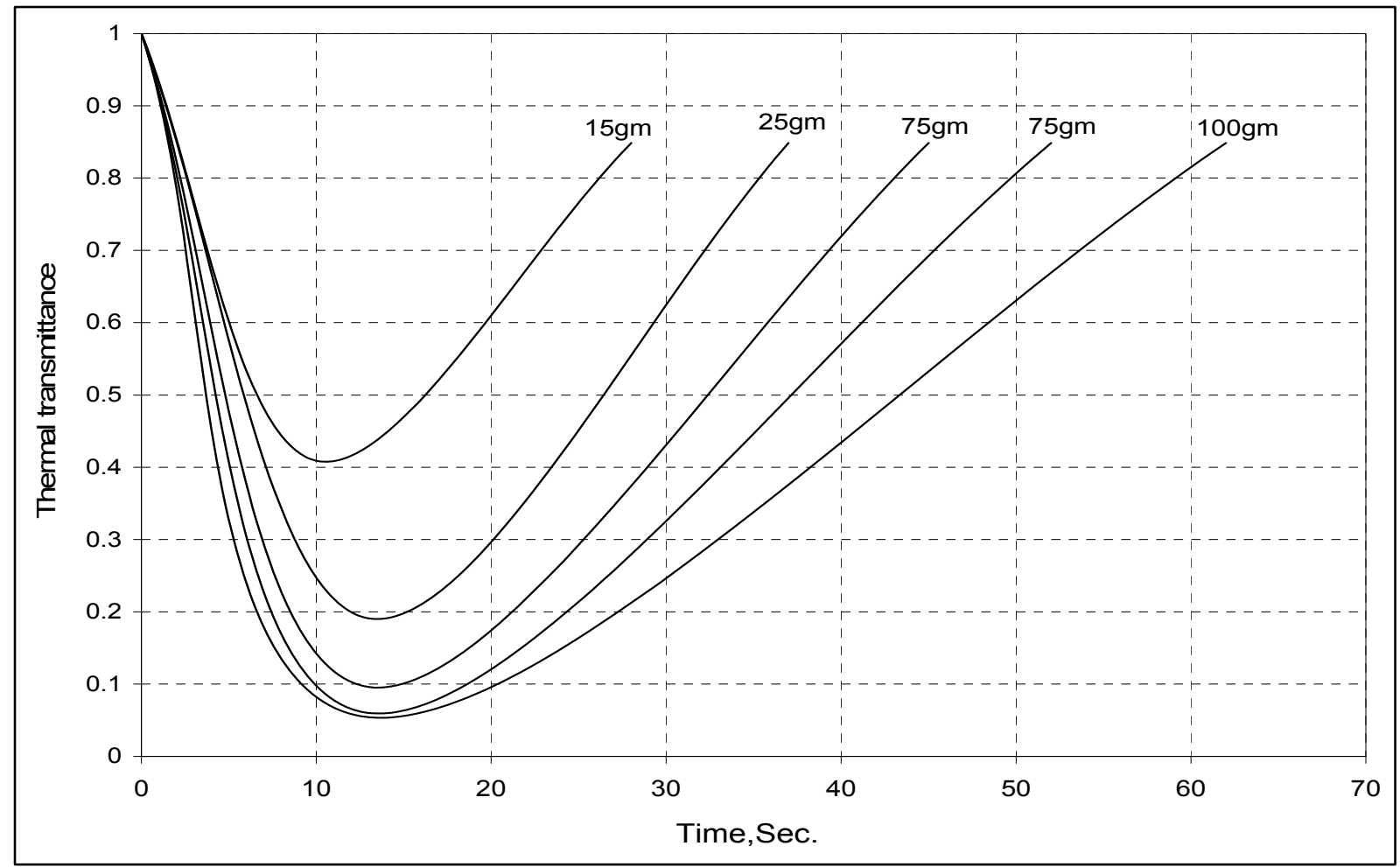

Figure (3.2) the attenuation of infrared radiation emitted from black body radiator at $100 \mathrm{oC}$ by mixture (2) at relative humidity $35 \%$ and $180 \mathrm{C}$ ambient temperature 


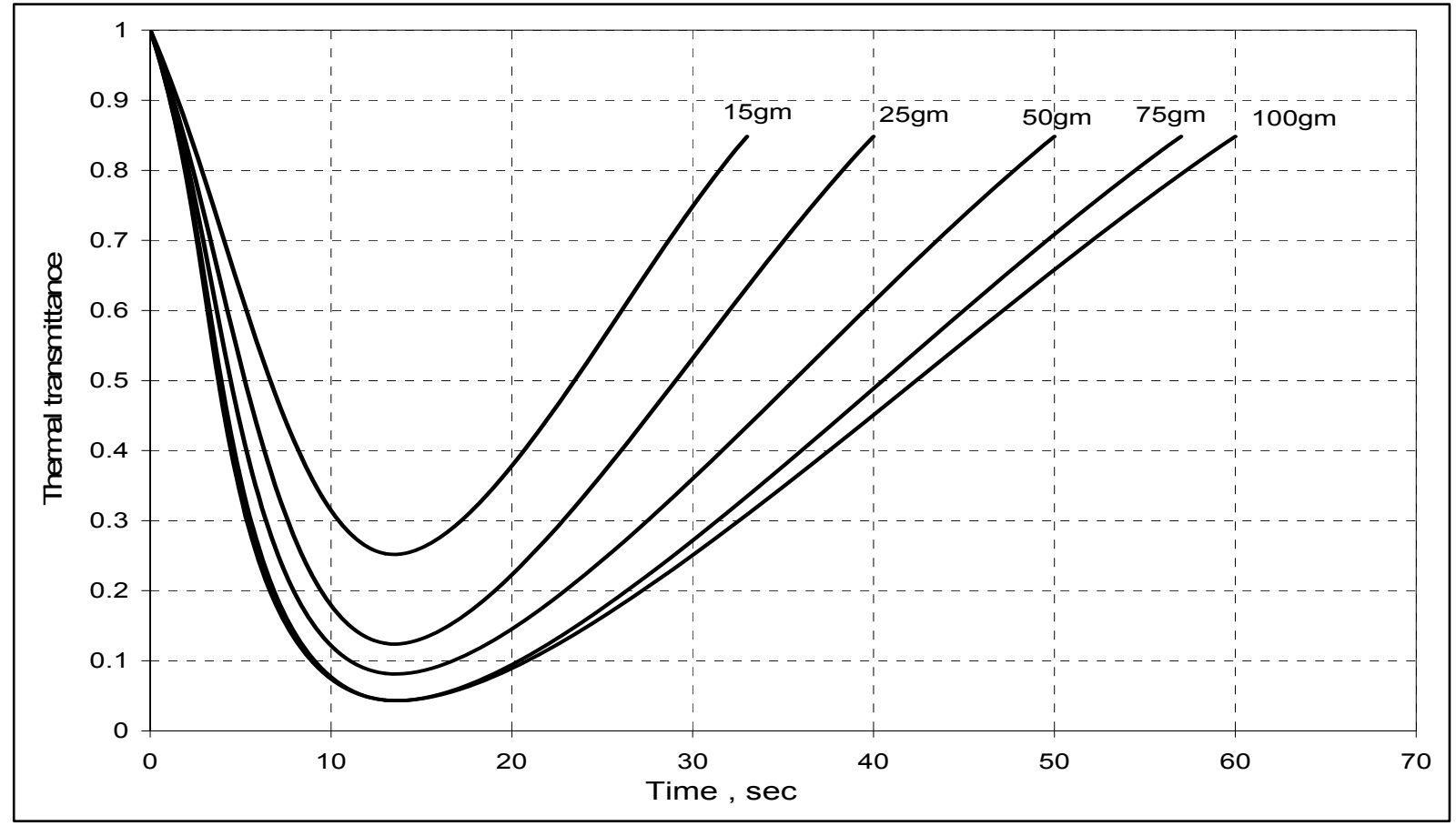

Figure (3.3) the attenuation of infrared radiation emitted from infrared black body radiator at $100 \mathrm{oC}$ by mixture (3) at relative humidity $35 \%$ and $180 \mathrm{C}$ ambient temperature

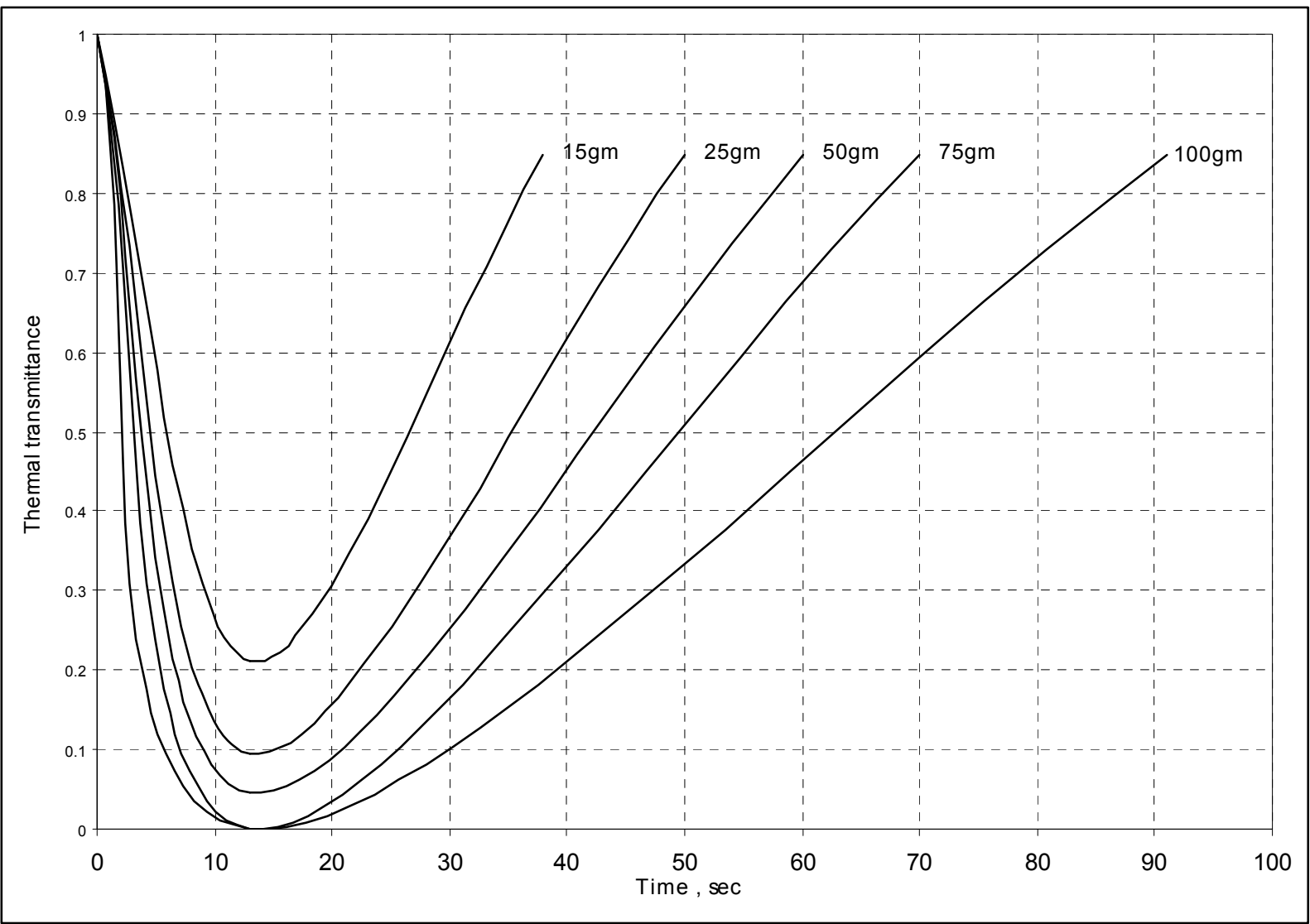

Figure (3.4) the attenuation of infrared radiation emitted from infrared black body radiator at $100 \mathrm{oC}$ by mixture (4) at relative humidity $35 \%$ and $180 \mathrm{C}$ ambient temperature 


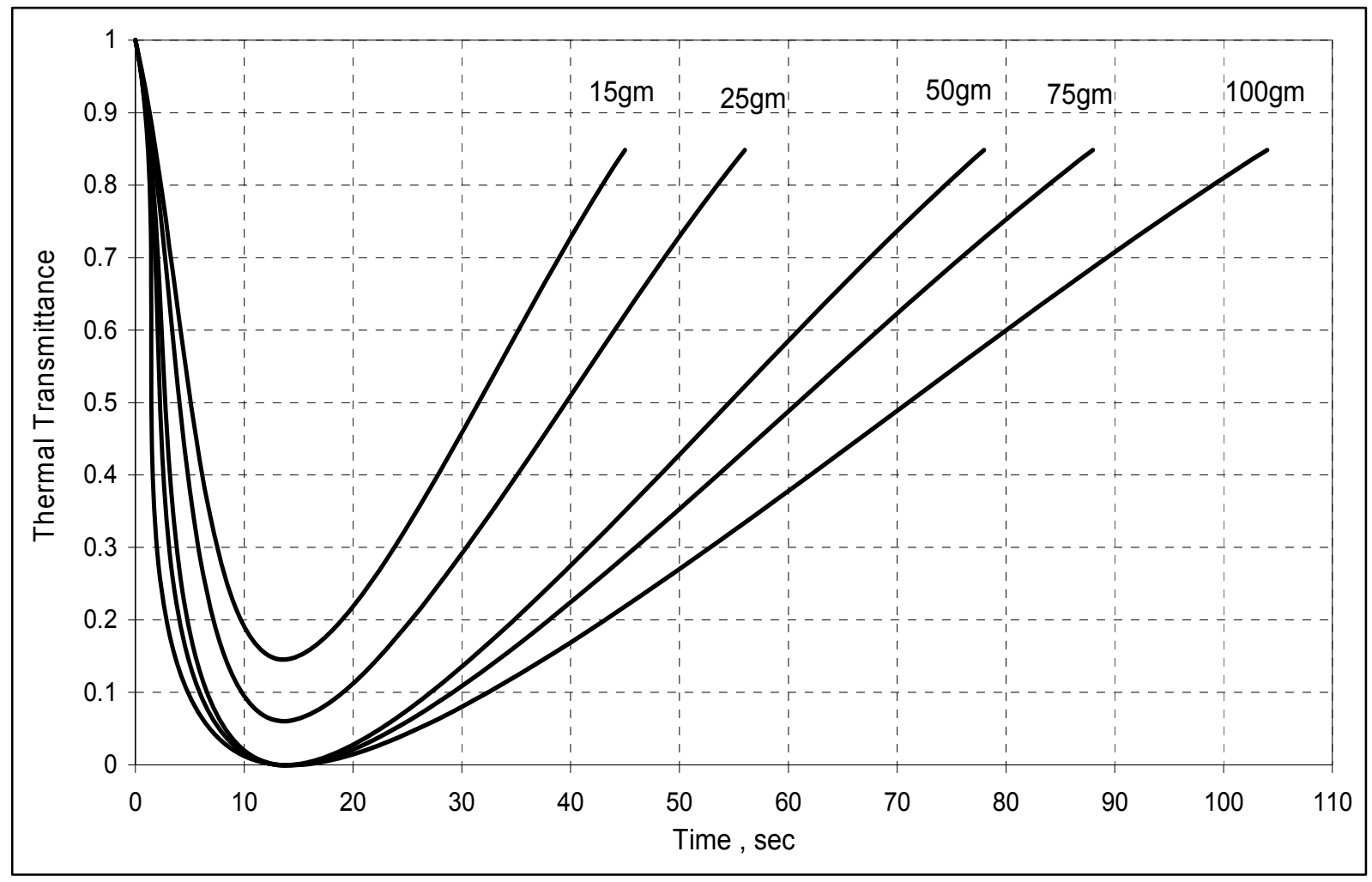

Figure (3.5) the attenuation of infrared radiation emitted from infrared black body radiator at $100 \circ \mathrm{C}$ by mixture (5) at relative humidity $35 \%$ and $180 \mathrm{C}$ ambient temperature

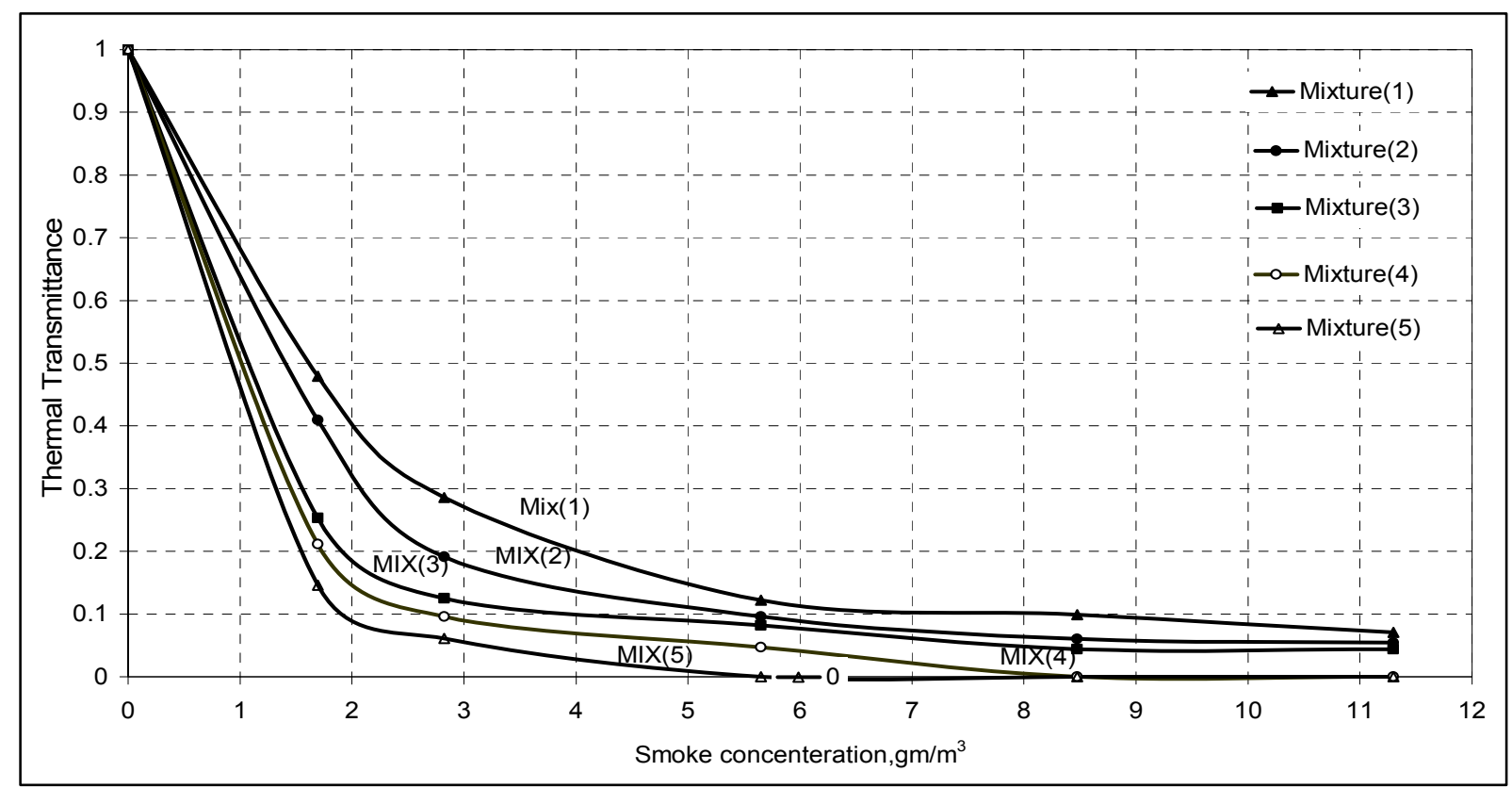

Figure (3.6) the effect of carbon black and calcium carbonate smoke mixtures concentrations on the transmittance of infrared radiation of black body at temperature $100 \mathrm{oC}$, at relative humidity $35 \%$ and $180 \mathrm{C}$ ambient temperature 